\title{
CONSIDERAÇÕES SOBRE A DOCÊNCIA NO CURSO DE NUTRIÇÃO
}

\author{
CONSIDERATIONS ON TEACHING IN THE NUTRITION COURSE
}

Ingrid Cristina Ferreira da Silva ${ }^{1}$

Gisele Silva Lira de Resende ${ }^{2}$

\begin{abstract}
RESUMO: Este estudo é realizado nos aspectos relativos à eficácia da didática utilizada pelos professores dos cursos de nutrição, farmácia e enfermagem da cidade de Barra do Garças. Sendo mais adiante uma reflexão a respeito da necessidade da capacitação dos profissionais docentes. Trata-se de uma pesquisa básica de cunho qualitativo e quantitativo, aliando-se à pesquisa descritiva. A caracterização da amostra foi composta por 59 acadêmicos, tendo como critério de inclusão a participação do aluno em um dos três cursos da área da saúde abordados pela pesquisa, sendo esse aluno de uma instituição particular ou não, o estudo buscou enxergar o assunto abordado pela ótica do educando, sendo aplicado entre os meses de novembro e dezembro do ano de 2018. Os resultados obtidos demonstraram que os alunos não estão satisfeitos com as aulas ministradas e cobram dos professores maior incentivo, uma didática mais eficiente e principalmente trazer as disciplinas ministradas para a realidade do aluno. Posto isso, uma das maneiras de sanar esse problema foi a criação de especializações voltadas para a prática pedagógica dentro do ensino superior.
\end{abstract}

PALAVRAS CHAVE: Didática. Capacitação de professores. Ensino Superior.

ABSTRACT: This study is carried out in aspects related to the effectiveness of the didactics used by teachers of the nutrition, pharmacy and nursing courses in the city of Barra do Garças. Further on, a reflection on the need for the training of teaching professionals. It is a basic qualitative and quantitative research, in conjunction with descriptive research. The characterization of the sample consisted of 59 academics,

\footnotetext{
${ }^{1}$ Bacharel em Nutrição pelo Centro Universitário do Araguaia - UNIVAR. Especialista em Docência do Ensino Superior pelo UniCathedral - Centro Universitário Cathedral. E-mail: ingrid.cris.nutri@gmail.com.

2 Doutora em Educação, com Pós-doutorado em Educação e Saúde (UFMT). Bacharel em Serviço Social e Licenciada em Pedagogia. Coordenadora do Núcleo de Pós-Graduação, Pesquisa e Extensão do UniCathedral - Centro Universitário Cathedral. Professora nos cursos de Direito e de Pedagogia do UniCathedral - Centro Universitário Cathedral. E-mail:giselelira@hotmail.com.
} 
with the inclusion criterion of the student's participation in one of the three courses in the health area covered by the research, whether that student was from a private institution or not, the study sought to see the subject addressed by view of the student, being applied between the months of November and December of the year 2018. The results obtained showed that the students are not satisfied with the classes taught and demand from the teachers greater incentive, a more efficient didactic and mainly to bring the subjects taught to them. the student's reality. That said, one of the ways to remedy this problem was to create specializations aimed at teaching practice within higher education.

KEYWORDS: Didactics. Teacher training. University education. 


\section{INTRODUÇÃO}

Esta pesquisa tem como tema "A eficácia da didática utilizada nos cursos de farmácia, nutrição e enfermagem da cidade de Barra do Garças-MT". Tendo em vista que o professor universitário assume funções diversas no âmbito da educação, onde as múltiplas funções exercidas e os avanços científicos da atualidade, principalmente na educação, trazem à tona a necessidade de uma capacitação de qualidade aos docentes universitários, afim de que sua principal função seja alcançada, que é a excelência no processo de ensino-aprendizagem.

As informações levantadas ao longo do desenvolvimento dos cursos de nível superior demostraram que a maior queixa dos acadêmicos estaria voltada à falta de didática dos professores presentes em sala. Com isso, passou-se a discutir a necessidade de uma formação pedagógica voltada ao ensino superior. Ademais, o professor passou a ser enxergado como um ser humano que necessita ter uma visão de mundo, sociedade e educação que fossem compatíveis com as caraterísticas de sua função.

É possível perceber que a maior parte dos professores universitários enxerga o momento da sala de aula apenas como lugar de transmissão de conhecimento, principalmente por meio de aulas expositivas, muitas vezes não se atentando para as inovações pedagógicas e tecnológicas. Cabe a esse profissional um papel significativo de, através da didática, conseguir relacionar o conteúdo ministrado na disciplina às habilidades de comunicação dos conhecimentos, não obstante, considerar as escolhas dos recursos instrucionais e instrumentais de aula.

Dessa maneira, esta pesquisa tem como problema: Em que medida os acadêmicos do último ano dos cursos de farmácia, nutrição e enfermagem, estão satisfeitos com a didática utilizada pelos professores? A partir dessa problemática buscou-se realizar uma análise mais abrangente acerca das didáticas ofertadas em sala de aula e sua eficácia no processo de ensino-aprendizagem. 
Acredita-se que a didática utilizada em sala de aula pelos professores do ensino superior está sendo ineficiente para o sucesso do processo de ensinoaprendizagem, o que pode estar atrelado ao fato de grande parte dos docentes não possuir capacitação pedagógica e não ser exigido por lei a especialização em docência no ensino superior para atuação em sala de aula. Ademais, pode-se levar em conta o fato de que as disciplinas da área pedagógica não fazem parte da grade curricular de formação em cursos de bacharelado.

Ainda pode-se admitir que embora a ciência pedagógica tenha avançado, a maioria dos profissionais docentes faz uso de uma didática tradicional, esta, por sua vez, mostra-se ineficiente para atender às necessidades do indivíduo da atualidade no seu processo de formação acadêmica e enquanto cidadão.

Trata-se de uma pesquisa básica, cujo objetivo foi tratar a respeito do tema: "A eficácia da didática utilizada nos cursos de farmácia, nutrição e enfermagem da cidade de Barra do Garças-MT". Defronte às questões lançadas neste artigo e a forma de abordagem do problema colocado, a pesquisa teve cunho quantitativo e qualitativo, pois além da tradução de opiniões em números para posteriores análises, também esteve em foco a análise da eficácia dos tipos de didáticas utilizadas.

A pesquisa descritiva enquadrou-se como mais adequada para lidar com as informações coletadas, sendo por meio dessas informações que foram discutidas as possíveis falhas na didática empregada dentro dos cursos selecionados para o estudo.

Esta pesquisa caracterizou-se também como bibliográfica, pois contou com a busca teórica em bibliografias como: livros, artigos, sites e periódicos. Estes foram imprescindíveis para fundamentar as teorias da pesquisa em questão. Foi ainda realizada a pesquisa de campo, constituída de um questionário fechado e estruturado. O questionário foi aplicado aos acadêmicos através do Google Formulários.

Diante disso, o método de abordagem da pesquisa foi o dedutivo, que consistiu na análise do todo para uma parte, tendo em vista a análise da situação nacional da educação no ensino superior, até a realidade detectada na cidade de Barra do Garça-MT. No tocante ao método procedimental, o método histórico 
apresentou-se de maior funcionalidade para a pesquisa, uma vez que, parte-se da investigação dos acontecimentos passados na aérea da educação, levando-nos à possível compreensão da natureza dos problemas enfrentados no ensino superior da atualidade.

O exercício da didática no ensino superior precisa ser enxergado como uma prática crucial e de construção diária, que precisa fazer parte do cotidiano dos educadores e não somente descritas como um instrumento metodológico fundamental. É mister que as universidades disponibilizem aos docentes especializações voltadas à prática pedagógica e que impulsionem uma reflexão sobre o processo de ensino-aprendizagem vivenciado dentro de sala.

Com fulcro na Lei 9.934 de 20 de dezembro de 1996, artigo 43, é proposto ao aluno do ensino superior o estímulo à criação cultural e ao desenvolvimento reflexivo, o que é pouco observado na maioria das universidades brasileiras. A busca por uma didática que melhor se encaixe na realidade dos estudantes e que promova um melhor processo de ensino- aprendizagem, visando atender às exigências esperadas de um aluno universitário é preciso. Cada dia mais é enfatizado que o professor do ensino superior deve possuir habilidades pedagógicas, não se sentindo o detentor do saber absoluto, mas que seja um pesquisador no preparo das suas atividades e que alcance uma aula atraente e prazerosa.

Destarte, a pesquisa em questão almejou identificar a eficácia da didática utilizada nos cursos postos em questão, para que fosse discutido se esses alunos estão realmente chegando ao que é proposto a um acadêmico universitário, uma vez que, eles, além de cidadãos aptos nas diferentes áreas de conhecimento, devem também participar diretamente do desenvolvimento da nossa sociedade. Não obstante, a pesquisa pôde evidenciar o fato de que algumas didáticas não são mais eficazes, o que faz com que repensemos nosso sistema de educação, afim de propor um conjunto de princípios que revejam as formas tradicionais do ensino. 


\section{RETROSPECTIVAS HISTÓRICA DA DIDÁTICA}

A palavra didática originou-se do grego didaktiké, que tem sido traduzido como: "técnica ou arte de ensinar". A didática é constituída de um conjunto organizado de estratégias utilizadas pelos professores, objetivando o desenvolvimento do aluno no processo ensino-aprendizado (SANTOS; DA LUZ, 2013).

Partindo das ideias filosóficas de Jan Amos Comenius com a 'Didactica Magna', e da contribuição de autores como Jean Jacques Rousseau , Johann Heinrich Pestalozzi e Johan Friederich Herbart, a didática a partir do início do século XX passou a receber contribuições de áreas como biologia e a psicologia, o que fomentou os questionamentos a respeito da eficácia da didática do modelo tradicional utilizado nas escolas (GIL, 2006).

No período entre os anos de 1549 a 1930 os jesuítas eram os educadores da época, trabalhavam com a catequese com o foco nos indígenas, contudo ofereciam aos burgueses uma educação diferenciada, sendo este um ensino humanista, universal e cristão. A educação no período do Brasil colônia não era vista de forma importante, sendo apenas uma forma de controle dos colonos nativos (VEIGA, 2002).

O ensino era baseado no Ratio Studiorum, trazendo orientações para ensinamentos universais, os jesuítas possuíam uma pedagogia dogmática, com exercícios de memorização e de desenvolvimento do raciocínio, contrário ao pensamento crítico. A didática utilizada nessa fase do país foi conhecida como "tradicional", esta por sua vez, enxergava o professor como detentor do saber e o aluno como tábula rasa, que não trazia consigo nenhum conhecimento prévio, sendo visto como receptor do conhecimento passado pelo professor. O modelo de ensino dos jesuítas não trouxe contribuição para o desenvolvimento da vida social e econômica da colônia. O ensino através do Ratio Studiorum influenciou a educação no Brasil até a expulsão dos jesuítas em 1759 (VEIGA, 2002). 
Entre 1930 a 1945, após a primeira guerra mundial institui-se uma valorização da educação, no intuito de difundir o ensino e extinguir o analfabetismo no Brasil. A crise do café no Brasil levou à implantação do Ministério da Educação e Saúde na década de 30. No final deste decênio, em 1939, foi decretada a Lei 1190/39, que instituiu a didática como curso e disciplina. Identificada a insuficiência da didática tradicional, ocorre o surgimento do escolanovismo, fomentado por movimentos de reforma escolar ocorridos da Europa e na América, estes movimentos surgiram a partir de um contexto histórico-social focado na industrialização e cercada por ideias liberais. A escola nova enxergava o professor como o facilitador do desenvolvimento escolar, e o aluno como construtor do seu próprio conhecimento (GIL, 2006).

De 1945 a 1960, era vivenciado um período com ideias de democracia liberal e de conflitos ideológicos que culminaram em uma reforma no sistema escolar do país, com importação de tecnologias educacionais advindas dos Estados Unidos. Com a crise da pedagogia nova, ocorre a chegada de tendências tecnicistas no Brasil, focado na racionalidade e alta produção eficiente. Na didática tecnicista o professor e o aluno ocupavam uma posição secundária, sendo meros executores do processo burocrático (VEIGA, 2002).

Findo o período do governo militar no final da década de 1980 e a consequente redemocratização do país, os professores reintegraram-se na participação das políticas educacionais. Com o fito de transpor a fase tecnicista, durante a formação dos docentes foi incorporado um discurso sociológico, filosófico e histórico. Com isso a prática crítica passa a ser cobrada também dos alunos, o que faz com que os professores comecem a repensar suas práticas pedagógicas, com a finalidade de torná-las cada vez mais voltadas para a realidade sociocultural (VEIGA, 2002).

\subsection{A IMPORTÂNCIA DA DIDÁTICA NO ENSINO SUPERIOR}

O panorama atual da educação tornou-se cada vez mais exigente, sendo comum nos cursos de nível superior as queixas de alunos com relação à didática do 
professor, com os levantamentos realizados pela literatura fica claro a deficiência da formação desses profissionais. Outrora, as competências educacionais preocupavam-se com a capacitação voltada à pesquisa, o que deixava implícito que isso fosse suficiente para a completude do docente. Por essa razão, a procura por uma formação continuada voltado para a área da docência tem crescido exponencialmente entre os que já lecionam (BORBA; SILVA, 2011).

Um fator discutido a respeito do professor universitário é a relação entre ensino e aprendizagem, muitos docentes centralizam suas aulas em sua própria pessoa, o que provavelmente advém da sua própria experiência de vida escolar, deixando claro sua opção pelo ensino. Estes professores acabam por passar suas aulas através de uma exposição coletiva, muitas vezes monologas, cabendo ao aluno apenas o papel de receptividade ou assimilação (BORBA; SILVA, 2011).

Contudo, existem professores que enxergam o aprendizado dos alunos como fator principal do processo educacional, voltando sua preocupação em identificar e desenvolver as aptidões, condições e expectativas dos discentes. Com isso, o professor passa a auxiliar o aluno, deixando de lado um papel de predomínio. Partindo desse cenário, o processo de educação deixa de ser a "arte de introduzir ideias na cabeça das pessoas, mas de fazer brotar ideias" (WERNER; BOWER, 1984).

A partir das políticas públicas em educação, foram proporcionadas condições de financiamento e de bolsa para o ingresso nas faculdades, bem como o aumento no número de instituições de ensino construídas no país, ocorreu um aumento exponencial no número de ingressante no ensino superior, consequentemente aumentou-se a necessidade de profissionais cada vez mais qualificados para as salas de aula (SANTOS; DA LUZ, 2013).

No tocante aos cursos da área da saúde, as técnicas de ensino seguem dois modelos básicos: aulas teóricas, de modelo expositivo e auxiliadas por retroprojetores ou lousa; e aulas práticas, realizadas em laboratório e/ou ambulatórios. Somado este fato à inexistência de disciplinas de cunho pedagógico nos cursos de bacharelado, podemos compreender o motivo da continuidade de uma didática tradicional dentro dos cursos da saúde, embora já tenha sido admitida sua insuficiência (CASTANHO, 2002). 
Posto isso, resta evidenciada a necessidade de incluir uma formação pedagógica aos profissionais da saúde, buscando a inserção de inovações tecnológicas e o estímulo ao desenvolvimento crítico, tornando os discentes ativos, as aulas mais proveitosas e a aprendizagem significativa para o educando (CASTANHO, 2002).

\section{RESULTADOS E DISCUSSÃO}

A caracterização da amostra foi composta por 59 acadêmicos dos cursos de nutrição, farmácia e enfermagem das diversas faculdades que ofertam estes cursos na cidade de Barra do Garças-MT, tendo como critério de inclusão a participação do aluno em um dos três cursos da área da saúde abordados pela pesquisa, sendo esse aluno de uma instituição particular ou não, o estudo buscou enxergar o assunto abordado pela ótica do educando, sendo aplicado entre os meses de novembro e dezembro do ano de 2018.

O questionário desenvolvido e a tabulação de dados foram realizados com o auxílio das ferramentas do Google Formulário, já a questão aberta foi tabulada a partir da análise de conteúdo das respostas obtidas de cada participante, sendo observados os problemas que eram relatados mais frequentemente ou que eram mais pertinentes. Os questionários foram enviados através dos aparelhos de telefone móvel de cada participante de forma individual e anônima, juntamente com o termo de consentimento para participação.

Dentre os participantes $83,1 \%$ cursavam nutrição, sendo estes os participantes mais expressivos. 11,9\% farmácia e 5,1\% enfermagem. O primeiro questionamento do formulário foi relacionado à satisfação do acadêmico com os docentes de sua instituição, de maneira que o aluno respondesse à pergunta chave antes de ter acesso às demais questões, evitando que este pudesse ser influenciado no decorrer do questionário.

De acordo com a primeira pergunta realizada aos acadêmicos, um percentual de $66,1 \%$ dos acadêmicos a princípio afirmou estar satisfeito com a didática utilizada 
pelos seus professores durante o curso. Ao serem questionados a respeito das características da didática dos seus professores (Figura 1), 47,5\% afirmou que a didática utilizada pelos seus professores seria razoável e suficiente para que se entendesse os conteúdos e os memorizassem.

Tal questionamento demostrou a visão tradicional que os discentes possuem do processo de ensino-aprendizagem dos seus professores, muito embora não consigam identificar o tipo de didática, foi possível perceber que os alunos não são receptivos a esse modelo de ensino. De acordo com José Carlos Libaneo (1992), o ensino tradicional possui maior ênfase na formação de hábitos, e na memorização, visando conceitos, fórmulas e exercícios, focado no método da repetição.

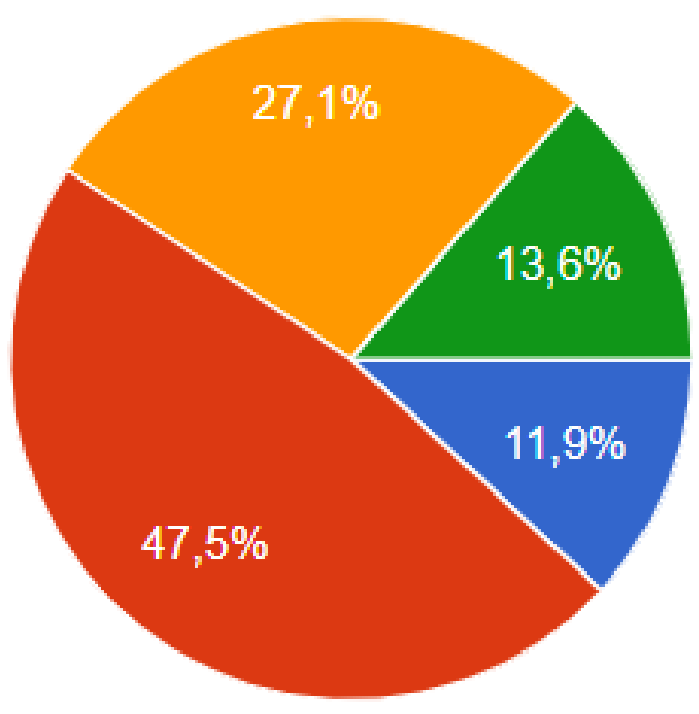

Ela é sofrível e não consigo entender os conteúdos;

Ela é razoável e suficiente para que eu entenda os conteúdos e memorize para as avaliação;

Ela é boa e consigo entender os conteúdos;

Ela é ótima, consigo entender bem e promover discussões relacionadas aos conteúdos.

Figura 1 - Didática utilizada pelos professores na visão do educando.

$\mathrm{Na}$ abordagem tradicional o professor é o foco do processo, cabendo ao aluno o papel de assimilação das informações através de aulas expositivas, memorizações e a reprodução do que fora ministrado durante o processo de avaliação. Para Freire (2007) o método tradicional é expresso como uma educação "bancária", ou seja, o educador é responsável por depositar de forma gradativa as informações na cabeça dos seus alunos, por fim os "extratos" fiéis são retirados durante o método avaliativo. É sabido que o método tradicional de ensino não satisfaz as necessidades da 
contemporaneidade em que estamos inseridos, contudo ainda é amplamente percebida sua presença dentro das salas de aula.

No terceiro questionamento buscou-se explorar a preferência dos alunos, identificando o que seria ideal na visão dos educandos. Para tanto, as alternativas utilizadas foram elaboradas levando em consideração características de cada didática abordada pelo estudo. Nesse momento foi possível identificar que $47,5 \%$ dos acadêmicos preferiam aulas que os envolvessem em grupos de trabalho com o auxílio do professor.

Esse modelo preferido por eles traz características similares com a didática conhecida como "escolanovista", este modelo de ensino surgiu com o intuito de revolucionar a educação tradicional, o aluno passou a ser sujeito principal da sua educação num processo natural, aprendendo por si só, cabendo ao professor o incentivo, orientação e organização da sala de aula. Contudo, esse modelo de ensino acabou sofrendo várias críticas, principalmente por deixar o aluno muito à vontade e não exigir nada dele (GIL, 2006).

Tal resultado demostra incoerência com as respostas anteriores, uma vez que os alunos afirmaram estarem satisfeitos com o modelo de aula ofertado, atribuíram ações dos docentes que caracterizavam métodos do modelo tradicional de ensino, contudo, em seguida apontaram sua preferência pessoal por aulas que envolvessem os alunos e professores em debates e análises críticas do contexto social, tal preferência discorda da didática tradicional e aponta uma inconsistência na resposta chave do questionário, que abordava a satisfação ou não do acadêmico. Ao longo das perguntas os alunos passaram a refletir sobre suas respostas, o que modificou totalmente o resultado inicial de satisfação. 


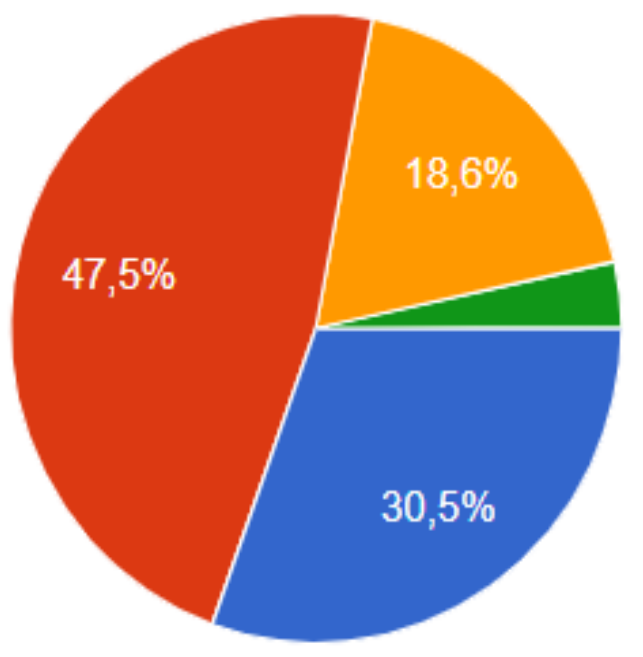

Aulas que envolvam os alunos em trabalhos em grupo, com auxílio do professor;

Aulas que envolvam alunos e professores em debates e análises críticas do contexto social;

\section{Aulas que conduzam os alunos de} forma objetiva para a avaliação.

Aulas expositiva somente;

Figura 2 - Modelo de aula ideal na visão dos educandos.

Ao serem questionados a respeito do modelo de aula ofertado pelos seus docentes $42,4 \%$ dos acadêmicos afirmaram que os professores em suas aulas assumiam um papel de facilitador do aprendizado, deixando-os à vontade quanto ao que desejavam aprender e os alunos construíam seu próprio conhecimento. 25,4\% afirmou que as aulas eram produtivas e despertavam o pensamento crítico e reflexivo, tornando os alunos capazes de modificar a realidade social em que estão inseridos. $20,3 \%$ caracterizaram as aulas dos seus professores como objetivas sendo o professor um transmissor de conhecimento de forma mecanizada, sem levar em consideração o contexto social.

A última questão da pesquisa foi aberta para que os participantes expusessem sua opinião quanto ao que os docentes poderiam fazer para que suas aulas fossem mais motivadoras e produtivas. A partir das respostas obtidas foi possível reafirmar o que foi observado ao longo do questionário, embora a maioria afirmasse satisfação com seus professores, a questão aberta mostrou o contrário, apenas $3,3 \%$ dos alunos estavam realmente satisfeitos com a didática de seus professores. Dentre as principais queixas, estava o pouco incentivo e interesse dos docentes, seguido da "falta de didática", má utilização dos recursos metodológicos e falta de aulas práticas que demonstrassem a aplicabilidade do conteúdo estudado dentro da sociedade. 
Os principais pontos abordados pelos acadêmicos refletem fortemente no preparo dos profissionais docentes para a sala de aula. De acordo com Masseto (2003), dentre os grandes desafios que os professores se deparam está principalmente na construção de práticas pedagógicas que permitam o êxito do ensino e aprendizagem e o desenvolvimento ativo nos debates em sala de aula pelos acadêmicos. Tal afirmação do autor reforça os resultados desse estudo, deixando claro a necessidade de se ter professores realmente capacitados para a prática docente.

Masseto (2003) afirmou em seu estudo que muitos professores acreditavam que se soubessem o conteúdo, automaticamente saberiam passá-lo adiante sem a necessidade da prática pedagógica. Contudo, em seu estudo o autor evidenciou que os principais modelos de ensino utilizados na época já não eram satisfatórios. Todos esses pontos abordados e os resultados dessa pesquisa nos permitem observar que a didática utilizada pelos professores tem sido insatisfatória para o êxito do processo de ensino-aprendizado na cidade de Barra do Garças, uma vez que a sociedade está em constante modificação e que a educação do aluno de ensino superior está atrelada ao modelo de sociedade e às necessidades contemporâneas.

A Lei de Diretrizes e Bases (LDB 9394/96), trata da formação de professores em seu Art. 66: "A preparação para o exercício do magistério superior far-se-á em nível de pós-graduação, prioritariamente em programas de mestrado e doutorado" (BRASIL, 1996). Diante disso, é possível observar que o requisito mínimo para ser professor no ensino superior é possuir pelo menos uma especialização, não importando em termos legais a formação pedagógica do docente. A questão da formação pedagógica nos cursos da área da saúde tem sido bastante discutida na atualidade, haja vista que a grade curricular desses cursos não aborda as práticas pedagógicas, muito embora a docência seja uma das principais linhas de atuação desses profissionais.

Ainda dentro dessa legislação (LDB 9394/96), temos que:

Art. 52. As universidades são instituições pluridisciplinares de formação dos quadros profissionais de nível superior, de pesquisa, de extensão e de domínio e cultivo do saber humano, que se caracterizam por: (Regulamento) (Regulamento).I produção intelectual institucionalizada mediante 0 estudo 
sistemático dos temas e problemas mais relevantes, tanto do ponto de vista científico e cultural, quanto regional e nacional; II - um terço do corpo docente, pelo menos, com titulação acadêmica de mestrado ou doutorado; III - um terço do corpo docente em regime de tempo integral. Parágrafo único. É facultada a criação de universidades especializadas por campo do saber.

A realidade percebida no resultado do presente estudo concorda com o autor supracitado, uma vez que os professores dos alunos envolvidos na pesquisa possuíam titulações de especialistas a pós-doutores e as insatisfações relatadas pelos acadêmicos foram as mesmas.

Um estudo realizado em uma instituição de ensino privada no Rio Grande do Sul a respeito da percepção de profissionais da área da saúde sobre a formação em sua atividade docente, demostrou que os professores em sua maior parte eram especialistas na sua área, mas demonstravam uma enorme falta de uma formação pedagógica. O estudo revelou ainda que havia um entendimento da parte dos docentes que o profundo conhecimento e habilidade técnica na sua área de atuação já seriam suficientes para compor um bom professor, desprezando a prática pedagógica (TREVISO; COSTA, 2015).

Em todas as etapas desse estudo, evidenciou o fato que exercer a docência pode ser muito mais complexo do que se imagina, requer habilidades que vão desde conhecer bem os alunos a quem se vai ministrar aulas e saber fazer uso das ferramentas necessárias, sendo assim:

[...] exige tanto uma preparação cuidadosa como singulares condições de exercício, o que pode distingui-la de outras profissões [...] o exercício da docência exige múltiplos saberes que precisam ser apropriados e compreendidos em suas relações. A ciência pedagógica situa-se nesse contexto e só com essa perspectiva contribui para a formação dos professores (CUNHA, 2010, p. 25).

Diante de todas essas observações realizadas por diversos estudos, algumas instituições de ensino, afim de corrigir as falhas em sala de aula, passaram a ofertar cursos no modelo de especialização lato sensu, surgindo assim as pós-graduações em Docência do Ensino Superior. Possuindo a capacidade de oferecer embasamento pedagógico principalmente aos profissionais oriundos de cursos 
bacharelados, o curso de docência no ensino superior vem tomando espaço significativo, principalmente nos cursos da área da saúde, uma vez provado que as habilidades técnicas e conhecimento especifico da área de formação contribuem para a atuação do professor, mas não consegue por si só ser suficiente para atuar no processo de ensino e aprendizagem com qualidade (GIL, 2010).

Portanto, o estudo reafirmou a hipótese que os alunos dos cursos de farmácia, nutrição e enfermagem das instituições de ensino da cidade de Barra do Garças, não estão realmente satisfeitos com a didática utilizada por seus professores, e isso se deve à falta do preparo pedagógico necessário ao docente e que não contempla os professores que possuem bacharelado. Desse modo, é evidenciado a extrema relevância das especializações em Docência do Ensino Superior para todos os professores universitários independente do seu grau acadêmico.

\section{CONSIDERAÇÕES FINAIS}

Este artigo acadêmico trilhou pelo caminho da pesquisa de campo mesclando dados estatísticos ao debate de ideias, com o objetivo de alcançar o entendimento acerca da eficácia dos tipos de didáticas utilizadas pelos professores no ensino superior dos principais cursos ofertados na cidade de Barra do Garças na área da saúde: nutrição, farmácia e enfermagem. O estudo atingiu seu propósito maior, comprovando o que já era verificado no dia a dia dos acadêmicos e em outros estudos similares.

As instituições as quais os entrevistados pertenciam valiam-se de profissionais desde especialista até pós-doutores, o que evidenciou o fato de que aprender a ensinar não é algo que está atrelado ao grau acadêmico do profissional, necessariamente. No que diz respeito à área da saúde, ainda existe a errônea ideia de que uma boa técnica prática unida a um amplo conhecimento conteudístico são suficientes para se criar um bom docente da saúde. Contudo é provado que o ato de 
lecionar vai além, pois as habilidades técnicas e o conhecimento científico são somente uma das faces da docência.

Diante da avalanche de possibilidades existentes para se ingressar em uma faculdade na atualidade, a capacitação e a formação dos docentes deve ser uma preocupação dessas instituições e do próprio profissional, haja vista que há uma imensa disponibilidade de ferramentas metodológicas capazes de auxiliar o professor, contudo este deve conhecer e saber fazer o melhor uso delas. Não menos importante, o docente precisa ter habilidade para conhecer sua sala de aula, possuindo uma visão holística capaz de ajudar seus alunos a enxergar as limitações e forças, trabalhando dentro da sua realidade.

A pesquisa mostrou que os discentes não se sentem satisfeitos com as aulas ministradas, não são estimulados, além de não enxergarem na sala de aula a utilidade prática de muitos conteúdos repassados pelos professores. Esses fatos geram uma sensação de tempo mal administrado e insegurança de atuação após formatura, além de deixar evidente a falta de preparo dos profissionais para estarem diante de uma turma.

Portanto, os dados da pesquisa mostram que os alunos do ensino superior não estão atingindo o que é proposto pela Lei 9.934/96, que caracteriza esse discente como criativo, com a capacidade de reflexão sobre a sociedade e com desenvolvimento cultural.

Ficou evidenciado a necessidade de algum tipo de formação complementar ou continuada para os profissionais docentes do ensino superior. Uma das soluções mais eficazes da atualidade tem sido através das especializações em Docência do Ensino Superior, que buscam desenvolver o profissional desde os recursos tecnológicos utilizados em sala de aula, até o desenvolvimento interpessoal entre docentes e alunos. 


\section{REFERÊNCIAS BIBLIOGRÁFICAS}

BORBA, Ernesto Oliveira; SILVA, Regina Nogueira. A Importância da Didática no Ensino Disponível

em: http://www.ice.edu.br/TNX/storage/webdisco/2011/11/10/outros/75a110bfebd8a88954e5f511ca9 bdf8c.pdf >. Acesso: 07 janeiros 2019.

BRASIL. Lei $n^{\circ}$ 9.394, de 20 de novembro de 1996. Estabelece as diretrizes e bases da educação nacional. Diário Oficial da União, Brasília, DF, 23 dez. 1996. Disponível em: < http://www.planalto.gov.br/ccivil_03/leis/>. Acesso em: 24 janeiro 2019.

BRASIL. Lei $n^{\circ} 1190$, de 04 de abril de 1939. Constituição da faculdade nacional de filosofia. Diário Oficial da União, Brasília, DF, 04 abr. 1939. Disponível em: < http://www.planalto.gov.br/ccivil_03/decreto-lei/1937-1946/Del1190.htm> Acesso em: 24 janeiro 2019.

CASTANHO, M.E. University level professors and their pedagogical practice in the healthcare area, Interface. Comunicação, Saúde, Educação. Campinas, 2002.

CUNHA, Maria Isabel da. Docência na universidade, cultura e avaliação institucional: saberes silenciados em questão. Rev. Brasileira de Educação, Rio de Janeiro, v. 11, 2010.

FREIRE, Paulo. Pedagogia da autonomia: saberes necessários à prática educativa. $36^{\mathrm{a}}$ ed. São Paulo: Paz e Terra, 2007.

GIL, Antônio Carlos. Didática do ensino superior.1. ed. São Paulo: Atlas, 2006.

GIL, Antônio Carlos. Didática do ensino superior. 5. ed. São Paulo: Atlas, 2010.

LIBÂNEO, José Carlos (2001). O essencial da Didática e o trabalho do professor: em busca de novos caminhos. Goiânia. Disponível em: www.ucg.br/site_docente/edu/libaneo/pdf/didaticaprof,pdf > Acesso em: 28 janeiro 2019.

MASETTO, Marcos Tarciso. Competência Pedagógica do Professor Universitário. 4. Reimpressão; Editora Sammus editorial; São Paulo, 2003.

SANTOS, Eniel do Espírito; DA LUZ, Luiz Carlos Sacramento. Didática no ensino superior: perspectivas e desafios. Saberes. Natal, 2013.

TREVISO, Patrícia; COSTA, Bartira Ercília Pinheiro da. PERCEPÇÃO DE PROFISSIONAIS DA ÁREA DA SAÚDE SOBRE A FORMAÇÃO EM SUA ATIVIDADE DOCENTE. Texto contexto enferm., Florianópolis, v. 26, n. 1, 2017.

VIEGA, Lima Passos Alencastro. A prática pedagógica do professor de didática. 7. Ed. Campinas:Papirus, 2002.

WERNER, David; BOWER, Bill. Aprendendo e ensinando a cuidar da saúde. 3. ed. São Paulo: Paulinas, 1984. 


\section{APÊNDICE}

APÊNDICE A - QUESTIONÁRIO DA COLETA DE DADOS:

ANÁLISE DA EFICÁCIA DA DIDÁTICA UTILIZADA PELOS PROFESSORES NO ENSINO SUPERIOR DOS CURSOS DE FARMÁCIA, NUTRIÇÃO E ENFERMAGEM DA CIDADE DE BARRA DO GARÇAS-MT.

Este questionário possui o objetivo de desenvolver um estudo científico, não sendo necessário identificações e apontamentos de pessoas ou instituições. As identidades dos entrevistados serão mantidas em total sigilo.

1 Qual curso você pertence?

( ) Nutrição

( ) Farmácia

( ) Enfermagem

2 Você é satisfeito com a didática utilizada por seus professores?

( ) Sim

( ) Não

3 Com relação à didática do professor, em sua opinião:

( ) Ela é sofrível e não consigo entender os conteúdos;

( ) Ela é razoável e suficiente para que eu entenda os conteúdos e memorize para as avaliações;

( ) Ela é boa e consigo entender os conteúdos;

( ) Ela é ótima, consigo entender bem e promover discussões relacionadas aos conteúdos. 
4 Com referência a forma de ministrar as aulas pelo professor, o que você prefere:

( ) Aulas que envolvam os alunos em trabalhos em grupo, com auxílio do professor;

( ) Aulas que envolvam alunos e professores em debates e análises críticas do contexto social;

( ) Aulas que conduzam os alunos de forma objetiva para a avaliação.

5 Em sua sala as aulas costumam ser:

( ) Expositivas, sem diálogo, com incentivo a memorização do conteúdo para avaliação;

( ) Voltadas para o que os alunos desejam aprender, o professor se comporta como um facilitador do aprendizado e os alunos constroem seu próprio conhecimento;

( ) Objetivas, com o professor como um transmissor de conhecimento, são mecânicas e levam em consideração a formação profissional e não a visão social; ( ) Produtivas, com o professor despertando o desejo de aprender, instigando o pensamento crítico e reflexivo, o que torna os alunos capazes de modificar a realidade social em que estão inseridos.

6 Em sua opinião, o que deveria ser feito pelo professor para que as aulas fossem mais motivadoras e produtivas?

7 Autorizo que as minhas respostas sejam utilizadas para o estudo científico em questão.

( ) Sim

( ) Não 